\title{
Sport policy convergence: A framework for analysis
}

\section{Barrie Houlihan}

\section{Abstract}

The growth in the comparative analysis of sport management processes and policy has led to an increased interest in the concept of convergence. However, the concept is too often treated as unproblematic in definition, measurement and operationalisation. It is argued in this paper that a more effective framework for examining claims of convergence is one that analyses the concept in terms of seven dimensions which can be explored through a mix of quantitative and qualitative methods of data collection. It is also argued that a deeper understanding of the process of convergence can be gained by operationalising the concept in the context of a selected range of meso-level theories of the policy process or of specific aspects of the process. The proposed analytic framework provides not only a definition of convergence, but also the basis for a more nuanced investigation of hypotheses of convergence.

Keywords: sport policy; convergence; policy change; comparative policy analysis 
Over the last ten years or so there has been increasing interest in the comparative analysis of sports systems and particularly of the extent and pattern of government support for sport. Many of the early comparative studies (Bennett et al., 1975; Rodger, 1978; Simri, 1979) were primarily descriptive rather than analytical. While much of the subsequent research concentrated on the identification of similarities and differences (Henry et al., 2007) there was a clear, but often implicit, concern with the concept of convergence (e.g., Houlihan, 1997; Riordan, 1978; Wilson, 1988). The most recent theoretically grounded studies (Bergsgard et al., 2007; De Bosscher, 2007; De Bosscher et al., 2009; Green \& Houlihan, 2005; Houlihan \& Green, 2008; van Bottenburg \& De Bosscher, 2011) were more explicit in their concern with convergence, but tended to take the definition of the concept as selfevident rather than problematic. De Bosscher (2007, p. 246) for example noted the emergence of an "increasingly homogenous elite sport development system which is ostensibly based around a near uniform model of elite sport development with subtle local variations” which is a conclusion supported by Houlihan and Green (2008). Green and Houlihan (2005, p. 179) in their study of three countries identified "five common themes and tendencies" in elite development systems and Bergsgard et al. (2007, p. 255) concluded that “[o]ur study indicates that elite sport systems and policies do converge”. It is this emerging consensus regarding convergence, in relation to elite sport policy at least, which is point of departure for the present discussion.

The motivation for this review lies, in part, in a degree of dissatisfaction with the imprecision of the concept of convergence and, in part, with an awareness that in analyses of convergence in other policy sub-sectors such as welfare (Taylor-Gooby, 2003), law and order (Jones \& Newburn, 2002; Muncie, 2005), labour markets (McBride et al., 2001) and agriculture (Coleman \& Grant, 1998) researchers have reached highly qualified conclusions 
or have argued that, depending on the aspects of the policy process that have been selected, convergence and divergence coexist. Others still (e.g., Radaelli, 2005) have argued that policy diffusion does not necessarily lead to convergence. Consequently, a central concern of this paper is to build on the earlier comparative analyses of sport policy by refining the concept of convergence in order to develop a more effective and nuanced framework for analysis. Related to this central concern are two issues, first, the propensity to confine analyses of convergence to the more accessible aspects of policy, such as inputs and implementation processes, rather than to explore the relationship between them and more deeply embedded societal structures, interests, processes and values; and second, the tendency to treat the concept of 'similarity' as unproblematic. These propensities are reflected in the more frequently quoted definitions of convergence. For example, Drezner (2001, p. 53) defines convergence as "an increase in the similarity between one or more characteristics of a policy across a given set of countries”. The definition offered by Kerr (1983, quoted in Bennett, 1991, p. 215) is slightly broader and defines convergence as "the tendency of societies to grow more alike, to develop similarities in structures, processes and performances”. However, even this definition does not explicitly encourage the examination of the interconnection between convergence in aspects of policy and convergence in more deeply rooted societal values and norms. Even if the focus is limited to convergence in characteristics, processes and structures it is often unclear which characteristics, processes and structures are significant in drawing conclusions and how similar they need to be before they can be declared convergent. In particular, it is argued that the analysis of convergence is, at best, highly partial if it does not seek to examine the relationship between convergence at the level of public policy and the more deeply rooted dimension of values and norms. The refinement of the concept of convergence is intended to enable researchers to address more effectively questions such as: 'Under what conditions can we expect convergence in sport 
policy?', What is the current extent, direction and pace of convergence?' and 'Is it possible to distinguish between shallow and deep policy convergence?'.

The paper begins with an interrogation of the concept of convergence and identifies a series of dimensions designed to add depth to analysis and give greater subtlety to the assessment of convergence. The discussion continues with an examination of a selection of analytic frameworks within which the dimensions can be effectively examined and concludes with a discussion of a series of methodological issues generated by the application of the framework.

\section{Dimensions of convergence}

The identification of relatively discrete dimensions of convergence runs two risks, the first is the simplification of the policy process and the second is that such a categorisation tends to reinforce a linear stage-based image of the policy process. However, the identification of distinct dimensions should not be taken as an endorsement of a simple linear view of the policy process, but rather as a useful heuristic device, an artificial construct, for exploring the empirical basis for claims of convergence and as an ideal type against which the more complex reality of policy-making can be thrown into sharper relief.

In the discussion that follows it is argued that it is possible to identify seven analytically distinct dimensions of the policy process that illuminate the debate on convergence. It is further argued that while these dimensions are analytically distinct they are integral elements of a holistic understanding of policy-making and must be understood in relation to each other and the process as a whole. The identification of the seven dimensions was the outcome of a review of existing comparative analyses of sport policy (especially, 
Bergsgard et al., 2007; De Bosscher, 2007; De Bosscher et al., 2009; Green \& Houlihan, 2005; Houlihan \& Green, 2008; Nicholson et al., 2011) and also a review of major comparative studies in other policy fields such as welfare (Cox, 2004; Vij, 2007), employment (Avdeyeva, 2006; Dunn, 2004; Fransen, 2011) and education (Alexiadou et al., 2010; Ozga, 2004; Raffe, 2004), Among the reviews of convergence theory those by Holzinger (2006), Bennett (1991) and Dolowitz and Marsh (2000) were particularly valuable sources informing the identification and refinement of the dimensions. The seven dimensions are summarised in Table 1 and their relationship is described in Figure 1.

\section{Table 1 about here}

Figure 1 about here

\section{Motives}

The significance of this dimension is that it is quite possible for countries to express similar public aspirations for sport, make similar patterns of resource allocation and select a similar mix of policy instruments yet be inspired by quite different motives. The discontinuity between means and ends is a common feature of comparative policy analysis and is amply illustrated in relation to elite sport (De Bosscher et al., 2009; Green \& Houlihan, 2005, Houlihan \& Green, 2008). Studies have found that countries have invested heavily and in a similar manner inspired by a diverse range of motives including the achievement of diplomatic recognition of sovereignty (former East Germany, see for example Guttmann, 1984; Strenk, 1978), the development/reinforcement of a sense of national identity (Canada, see Harvey, 2006; and the Soviet Union, see Peppard \& Riordan, 1993), the demonstration of ideological superiority (Soviet Union, see Peppard \& Riordan, 1993, United States, Davison, 
1995), the assertion of parity with a former imperial power (Australia, see Mandle, 1976) and the confirmation of a country's status as a world (economic) power (China, see Houlihan et al., 2010; Xu, 2009). Identifying and measuring change in motives is difficult as they tend to operate at overt and covert levels with the latter also varying in the degree to which they are consciously acknowledged. In addition, the analysis of motives highlights the permeability of the sport policy sub-sector and the extent to which sport is often a means to non-sport ends and consequently raises the question regarding the unit of analysis for convergence. Given the prominence of diplomatic and economic motives for funding elite sport it is at least arguable whether the analysis of convergence should focus on the foreign policy or economic policy sub-sectors rather than that of sport policy. Exploration of this dimension requires qualitative, and preferably longitudinal, analysis of policy documents, of the statements of policy actors and of the pattern of resource allocation. However, the time period over which the analysis should take place poses a particular methodological challenge which is discussed later in this paper.

\section{Agenda and aspirations}

'Agenda' refers to presence of issues related to sport within the decision-making processes of government and the obligation on government to respond (although the response may be to do nothing). How issues reach the public policy agenda is discussed below but suffice to say at this stage that they might reach the agenda in a variety of ways both exogenous (e.g. the UNESCO International Convention Against Doping in Sport requiring government action) and endogenous (e.g. countries in western Europe facing a common set of demographic trends such as an ageing population or effective lobbying by women's groups for greater equality of access to sports opportunities). The extent of convergence on this dimension could be measured through the analysis of a variety of indicators including trends in: the appointment of ministers responsible for sport; dedicated administrative capacity within 
government (departments or agencies); budget allocations to sport as a proportion of total budget; and committees of enquiry, questions/debates in Parliament.

While the inclusion of sport on the public policy agenda is an important indicator of the degree of convergence it is perhaps more important to assess how governments have responded to the inclusion (whether willing or due to imposition) of sport issues. The most common initial element in any governmental response will be some aspirational statement such as 'to make participation in sport safe for young people', 'to secure a top ten place in the Olympic Games', or 'to eliminate match-fixing'. Measuring the sincerity of aspirations is always difficult and is usually judged according to whether the aspirations are translated into the commitment of inputs/resources (such as money, law/regulation and political legitimacy) or remain at the rhetorical level. Aspirations can vary in the degree of realism (achievability) and also in the degree of sincerity that underpins them. However, as a number of studies have demonstrated even when aspirations are feasible and sincerely held across a number of jurisdictions outputs and impact can vary widely as they are mediated by domestic institutional and cultural structures (Goldfinch, 2006; March \& Olsen, 1996). Thus while aspirations can be assessed by reference to indicators such as the seniority within the government of the person expressing them, the frequency of their expression/reinforcement, the number of senior figures expressing support, and the precision of any targets, the indicators with the greatest degree of validity are the commitment of resources and the pace at which aspirations are translated into policy implementation.

\section{Contextualising discourse/ideology/values}

For an effective understanding of the significance of contextualising discourses and the ideology and values they reflect it is necessary to think in terms of levels of embeddedness. Bachrach and Baratz (1962) used the concept of levels to explain 'non-decisions'. Benson 
(1982), drawing on Marxist ideas, identified three levels (administrative, interest structure and rules of structure formation) to explain how issues reach the public policy agenda, and Lindblom (1977), drawing on Weberian sociology, emphasised the embeddedness of a probusiness ideology among American public officials. Following the work of Benson in particular four reasonably distinct levels are described in Table 2.

\section{Table 2 about here}

Contextualising discourses range from the deeply rooted values and beliefs which are longlasting and relatively permanent structural constraints on policy through to the more ephemeral transit of ideas which are generally sector-specific, but which nonetheless impact on policy. As regards the former much has been written on the impact of culture on policy, especially welfare policy (Deacon, 2000; Esping-Anderson, 1990; Liebfried, 1992; Siaroff, 1994;). This literature provides strong evidence of the persistence of deeply-rooted orientations to policy priorities and responses often based on belief systems such as Calvinism, Catholicism and Confucianism. Of particular importance in shaping the relationship between government and sport organisations and the nature of government involvement in sport has been the more recent experience of government domination of sport for ideological purposes such as the Nazi domination of sport not only in Germany, but also in some of the countries that it occupied (for example Norway). The legacy of this experience has been to embed the autonomy of sport organisations in the contemporary culture and sometimes in the constitution. Change and possible convergence at this deep level of discourse is slow, but does occur as Greve (2011) has noted in relation to the Nordic model of 
welfare and Bergsgard et al. (2007) in relation to Norwegian and German sport policy. Such deep structural values or policy predispositions often manifest themselves as 'storylines' (Fischer, 2003) where historical ‘facts’ become embroidered and take on an ideological (or mythological) status that engenders a strong commitment to particular policy orientations, for example to the significance given to sport as an adult career or as part of child development or to the appropriateness of female participation in competitive sport.

Storylines which are associated with less deeply rooted discourses can nonetheless have an impact on policy. Slogans such as 'no compromise', 'competitive sport is character forming', and 'no gain without pain' are often, as Goldfinch and Wallis (2010, p. 1101) note, “content-less and divorced from theoretical underpinnings”, but often gain purchase in the decision-making process because they fulfil an important function of simplifying complex issues.

With regard to discourses, whether at the deep or shallow ends of the spectrum, it is important to bear in mind that they are not neutral, but reflect and serve particular interests. Their function in the policy process can be to shape the perception of problems and acceptable solutions, to reinforce the solidarity of coalitions of interest and to undermine opposition. For example, a dominant storyline in many countries is that competitive sport generates positive personal and community benefits. This dominance tends to unify an often influential coalition of PE teachers, national sport organisations (NSOs) and populist politicians who are able to exert tight control over the policy agenda and effectively undermine advocates of alternatives forms of sport participation. In relation to sport, discourses are important in shaping policy in a wide variety of areas including gender equity, the treatment of young athletes, the career support given to ex-elite athletes, and the emphasis given to Olympism. Measurement of convergence or divergence in underpinning discourses could be achieved through the application of qualitative thematic analysis to a range of 
sources including the policy statements of government, its main partners and the media as well as an analysis of the location of responsibility for an element of sport policy in the machinery of government. For example, Thomas (2008) traced over a thirty year period the shift in the discourse which contextualised disability sport from a therapeutic to a recreative model and Tanaka (2012) has drawn attention to the persistence of a medicalised/therapeutic model of disability sport in Japan as evidenced by the location of responsibility for disability sport in the Ministry of Health and Welfare rather than the Ministry of Sport, despite increased investment in elite level disability sport by the government and considerable success in the Paralympic Games. Also important would be formal governmental endorsement of values and policies expressed at the transnational level such as through the UN Convention on the rights of the child (United Nations 1989), the International Decade of Disabled Persons and the Convention on the rights of persons with disabilities (United Nations 2008). However, as Goldfinch and Wallis comment "Convergence on ideas does not mean a convergence on design or practice - and the power of ideas to drive reform can be limited by the interplay of politics, interests and institutions” (2010, p. 1104).

\section{Inputs}

Inputs refer to the mix of resources (finance, expertise, administrative capacity etc.) and the source of resources (whether from the public, commercial and not-for-profit sector) which enable policy responses by the government to be formulated. Inputs, along with the next dimension (implementation) are both elements of policy design. Inputs have been identified as a separate dimension due to the impact they have on the capacity of government to influence, if not determine, the implementation strategy (see Gough \& Abu Sharkh, 2011 for a discussion of the impact of funding sources on the development of welfare policies). Of particular importance is the extent to which governments are reliant (whether through 
preference or necessity) on inputs over which they have only limited control. For example, in some countries, the United States being the clearest example, the preference of the government for reliance on the college and commercial sectors to provide elite sport opportunities (especially in basketball, football, ice hockey and baseball) has resulted in having only limited leverage over the policy of those sports, towards doping for example. A further illustration concerns the increasing preference for governments to introduce lotteries as a significant source of funding for a wide range of sport policies, but especially for the support of elite sport aspirations. While lotteries tend to be under reasonably tight central government control it is usual for there to be some degree of discretion given to the lottery board. However, inputs are not limited to the financial and can also refer to resources such as administrative capacity, expertise and salience. The particular mix of inputs will constrain policy design. Data relating to the quantity and mix of inputs invested in a policy and how the mix changes over time should be relatively easily available from published sources. More difficult to determine will be the extent of influence governments have over the deployment of inputs and this information will probably need to be gathered through qualitative interviewing.

Both this dimension and the next pose the analyst with the difficult challenge of deciding the appropriate altitude (level of generality) from which to conduct the study. The problem is easily illustrated. An analysis may identify increased convergence between countries $\mathrm{X}, \mathrm{Y}$ and $\mathrm{Z}$ through an examination of trends in national budget allocations which shows that, over a ten year period, the gap in per capita spending on youth sport has halved. However, closer (lower altitude) analysis indicates that while ten years ago funding in all three countries was coming from the education budget, funding in country $\mathrm{X}$ is now predominantly from the welfare budget, in country Y from the sport ministry budget and only in country $\mathrm{Z}$ has education remained the main funder. In contrast to the earlier conclusion 
rather than convergence there is strong evidence of divergence. As is discussed below, the level at which analysis takes place will be largely determined by the particular research question. At this stage it is sufficient to note that the altitude at which the research takes place is a significant decision.

\section{Implementation}

Implementation refers to the selection of instruments and delivery mechanisms for a particular policy. It is in relation to the selection of instruments that the clearest examples of convergence are often found. Processes such as policy learning and transfer, mimetic isomorphism and exogenous pressure are often evident as mechanisms responsible for increased convergence and are discussed below. Generally, governments rely on a combination of three basic instruments for policy implementation - penalties (for example, the loss of subsidy for poor performance at the Olympic or Paralympic Games), inducements (such as subsidised community sports facilities; 'salaries' for full-time athletes and the award of honours) and information (for example, advertisements promoting the health benefits of physical activity) (Hood \& Margetts, 2007). However, over time governments develop preferences for the particular delivery mechanisms. Policy can be delivered by a central government department or agency, devolved to units of sub-national government, or subcontracted to the not-for-profit sector or to the commercial sector. For example, in the UK recent governments have preferred to deliver community sport through national governing bodies of sport and their club network rather than through municipalities. Coleman and Grant (1998, p. 225), in their study of agricultural policy, hypothesised that “[o]ver time ... convergence on content and instruments should lead to common outcomes”, but concluded that the adoption of particular instruments and the selection of the way in which those 
instruments should be used introduced considerable variation in policy at the point of contact with the target group.

Implementation refers not only to the selection of delivery mechanisms by central government but also to the process of mediating policy as it moves towards the point of delivery and the target population. The literature on implementation suggests that the journey that policy takes from policy-makers to the client/service user can be heavily mediated, reinterpreted and adapted, "by enclaves of difference, coalition and resistance” (Muncie, 2005, p.61) to suit conditions at the 'street level' (Pressman \& Wildavsky, 1984; Radaelli, 2005). Given the contribution of sports development staff, coaches, physical education teachers and club officials to the implementation of sport policy Lipsky’s (2010, p. 3-4) conceptualisation of the "street level bureaucrat" is of particular relevance to analyses of convergence. Arguing against a top-down view of policy implementation Lipsky suggested that as a consequence of their daily interaction with the public and the "substantial discretion in the execution of their work" street level bureaucrats "structure and delimit people's lives and opportunities” - that is they make policy. The emphasis that Lipsky gives to the operational necessity of adapting policy to the imperatives of the local context would appear to make the possibility of convergence more remote or alternatively its presence even more surprising.

Although the allocation of resources to policy implementation is an indication of a commitment to policy aspirations some caution is needed as it is possible to distinguish between policy as ‘action’ and policy as (mere) ‘activity’ ${ }^{1}$ Policy as action occurs when there is a reasonable expectation that the policy (i.e. allocation of resources, selection of instruments and delivery mechanism) is likely to have, or is intended to have, a positive impact on the problem being addressed whereas policy as activity, which may also involve some commitment of resources, has a less clear or persuasive policy design and often remains 
at the level of rhetoric. Policy as activity may be the result of uncertainty about how to tackle a problem or a reflection of the high expectations of the public or lobby groups combined with problem intractability. Much penal policy suffers from a surfeit of the latter and is evidenced by the trend towards longer prison sentences and wasting police time by having them walking along high streets. As Jones and Newburn (2002, p. 176) observe "[t]he object of such policies is primarily expressive ... rather than instrumental”, concerned less with substantive content than with style and symbolism (see Edelman, 1971). Much the same conclusion could be drawn in relation to recent attempts by the UK government to stimulated higher levels of community participation in sport.

The analysis of the dimension of implementation is part measurement and part categorisation. Categorisation, of type of instrument adopted, can be an important indicator of the extent of convergence. However, there is also scope for measurement within each type of policy, for example the scale of, and trends in, inducements or penalties or the size and trends in investment in information provision.

\section{Momentum}

Momentum refers to the intensity of commitment by powerful policy actors to the expressed aspirations and their continued commitment of resources beyond the initial phase of the policy process. Anthony Downs (1972) argued that policy often progresses through an 'issue attention cycle’ where 'alarmed discovery' generates enthusiasm for action, but is followed by the realisation of the costs of making significant progress which in turn leads to a gradual decline in public and governmental interest and often a discreet abandonment of initial aspirations by the latter. A recognition of the intractability of a problem and the absence of ‘quick wins' for the government often result in a loss of momentum - at least until public attention is reawakened by a new crisis. In relation to sport the many false starts in attempting 
to tackle the issue of match-fixing and the excess of rhetoric over action in relation to attempts to increase community level participation in sport are both illustrative in many western European countries of the relevance of the dimension of momentum.

\section{Impact}

Impact is, in many respects, the crucial dimension in any analysis of convergence and may be defined in terms of intended effects, i.e. the extent to which change has been achieved in line with policy objectives, and also in terms of unintended effects. An example of the unintended impact of a policy would be from the UK where the objective of improving the quality of youth coaches led to the introduction of more rigorous basic (Level 1) coaching qualifications which unintentionally led to a decline in the number of qualified coaches due to the cost of obtaining the qualification. As with analyses of policy impact the temporal dimension is crucial as a judgement has to be made regarding the time period over which one should expect the impact of a policy to be evident.

With regard to intended impacts it is not sufficient simply to demonstrate that the impact of a set of identified policies associated, for example, with the environmental consequences of sports mega-events has been to produce a greater degree of similarity (convergence) in a group of host countries. Much more important is the nature of the convergence identified and whether one has identified convergence characterised by a 'race to the bottom', regression to the mean, or 'catching up'. There can even be situations where there is policy movement in the same direction, but the pace of change is different with the consequence that countries appear to be becoming more divergent (Holzinger \& Knill, 2005).

Taking the welfare of young elite athletes as the example one possibility is that convergence implies a regression to the mean. In other words, some countries which are particularly neglectful of the welfare of young elite athletes will raise their standard of 
welfare provision while others that have high standards of welfare will lower their standards. The treatment of young athletes in China has improved in recent years (Hong, 2011) while the high welfare standards in Norway are under pressure (Bergsgard et al., 2007). A more problematic variant is the often mentioned outcome of neo-liberal economic policies in relation to welfare, namely a 'race to the bottom' where the intensity of competition between states for capital investment steadily erodes welfare standards and protection for employees. A parallel example in sport would be the neglect of the welfare and health of young athletes as the urgency to fast track the development of young talented athletes intensifies. A third variant is a general raising of standards to those popularly acknowledged as constituting the benchmark. In relation to community sport participation levels the UK government in its policy document Game Plan (DCMS/Strategy Unit 2002) aspired to reach the high levels of participation found in Finland. A fourth interpretation is as movement to an abstract set of standards such as those encapsulated in the World Anti-Doping Code (WADA 2009) or (in relation to young athletes) those reflected in the United National Convention on the Rights of the Child.

\section{Approaches to analysis and factors facilitating and inhibiting convergence}

Once the concept of convergence has been unpacked and reconstituted, for heuristic purposes, as a series of relatively discrete dimensions rather than a unitary phenomenon the more daunting problems of a) determining the relative importance of the seven dimensions and b) operationalising the concept as a tool for analysis still remain. As regards allocating a relative weighting to the dimensions one response is to argue that the weighting will be determined by the precise research question being investigated, whether, for example, the 
focus is on change in the public discourse regarding the place of sport in the school curriculum, government objectives for elite sport or changes in the machinery of government for service delivery. A second, though admittedly normative, response would be to argue that despite the pre-occupation with agenda-setting in much policy analysis the focus for convergence studies should be on impact i.e. the difference that sport policy makes to the lives of individuals and their communities. A third response would be to give greater weight to those dimensions, such as contextualising discourse and policy momentum, that reflect more directly deeply rooted social values as summarised in Table 2.

It is suggested that the analysis of convergence could be undertaken by pursuing the following three steps. The first is to undertake an assessment of the degree of similarity across a group of countries/jurisdictions in relation to the four dimensions for which empirical data are generally more easily available (agenda and aspirations, inputs, implementation and impact) (see Figure 1). Much of the data for this step in the analysis can be gathered from published sources supplemented by semi-structured interviews with key policy actors. For example, with regard to the analysis of agendas and aspirations much useful data can be gleaned from strategic plans, parliamentary debates and ministerial speeches with the usual caveat that aspirational statements should not always be taken at face value. Similarly, data relating to inputs and implementation should be reasonably easily accessible. The second step is to explore the nature of the relationship between these four dimensions as this is likely to identify where policy systems are more flexible and thus susceptible to convergence or more resistant to change. For example, in a number of countries there is an acknowledgement that most successful elite development systems tend to be highly centralised yet find it hard to construct a centralised system due to powerful inhibiting factors (such as strong federal systems or strong public antipathy to government intervention) which affects policy design. The final step is to assess the influence of the other 
three, more contextual dimensions, on policy. Momentum, for example, is in large part, reflected in the first four dimensions and soon becomes part of the context of policy insofar as it helps to create expectations for the policy in wider society. The longer established contextual factors such as deep structural values and dominant ideologies/ discourses exert a more profound, but far less visible, impact on dimensions such as inputs and implementation and give much credence to path dependency explanations (soft versions at least) of policy development.

In order to progress from using the dimensions simply for descriptive purposes and to using them as analytic concepts, allowing the researcher to address such questions as the conditions under which we might expect convergence to occur, it is essential to operationalise the dimensions within a theoretical framework. However, there is no single theoretical framework that is the obvious choice when studying convergence. Not only do the frameworks sensitise the researcher to very different aspects of policy and the policy process, but theories also vary by scope and ambition. The seven theories discussed below (see Table 3) have been selected according to two sets of criteria: first, there are those theories (regime theory, advocacy coalition framework and multiple streams) which are explicitly concerned with the analysis of the policy process, address a broad range of aspects of the policy process (such as agenda-setting, policy choice and implementation), and have been applied successfully in the analysis of sport policy. These types of theory are explanations of a particular social phenomenon, policy making, and as such aim to generate and test generalisable statements regarding relationships between variables (Abend, 2008; Hempel, 1965). The selection of a particular theory will often depend on the nature of the research focus or hypothesis to be tested. Thus the advocacy coalition framework might be considered an appropriate theory if the focus was on the changing domestic landscape for sport while a focus on the influence of international organisations such as UNESCO and the International 
Council of Sport and Physical Education on the physical education curriculum might lead the researcher to utilise regime theory. Alternatively, one might simply use these theories as sensitising reference points during the empirical investigation and use them to help interpret findings rather than guide the data collection process.

The second set of criteria apply to those theories (policy learning/transfer, mimetic isomorphism, path dependency and common circumstances) which are explicitly concerned with processes more directly relevant to analyses of convergence/divergence, but which are narrower in scope insofar as they focus on particular aspects of policy change. These types of theory are concerned to explore specific relationships relevant to an understanding of convergence/divergence, for example the relationship between organisations and their environment (mimetic isomorphism) or between current policy choice and policy history. It is quite legitimate to use these more narrowly focused theories in conjunction with the broader theories of the policy process.

\section{Table 3 about here}

Regime theory refers to a class of potential sources of convergence that rely on coercion and which can range from moral persuasion and socialisation to the application of international law and economic and military sanctions. Regime theory provides one of the most persuasive attempts to account for increasing convergence. Regimes are essentially global policy communities with relatively stable membership and a degree of formality that have been established, often but not always by governments, to promote particular norms and values and also to pursue specific policy aspirations (see Krasner, 1983; Houlihan, 2009). Some 
policy regimes are formal, such as that for anti-doping, and have documented policy aims (conventions or codes of conduct) reinforced by law and sanctions while others, such as that for women's equality in sport are less well resourced, less formal and have fewer sanctions available to enforce compliance and convergence.

Taking elite sport as an example the institutional network of governing bodies (international federations) and event organising bodies (for example, the International Olympic Committee and the Commonwealth Games Federation) provide a regulatory framework which dictates not simply the rules of play but also the criteria for eligibility for participation in the major international competitions. These organisations along with other global bodies such as the Court of Arbitration for Sport and regional organisations such as the Council of Europe and the European Union are very likely to have a substantial impact on national sport policy that extends beyond rules of play and eligibility. The direct involvement of government in some of these bodies and the indirect involvement through national governing bodies of sport is likely to have a significant socialisation effect on policy even if the pattern of contact is not used as an opportunity for deliberate policy learning and transfer. Thus what may well begin as a set of relationship required by quasi-legal regulatory obligations (NSO membership of the relevant international federation or a government's signature of the UNESCO Convention Against Doping in Sport) results in the internalisation of new norms which in turn leads to increasingly similar policy responses to associated issues. As Checkel argues, “[t]here is growing empirical evidence to suggest that what starts as strategic incentive-based cooperation within international institutions often leads at later points to preference shifts” (2005, p. 814; see also Risse et al., 1999). Others have argued that a form of anticipatory socialisation can take place whereby global norms and principles can begin to influence domestic policy before they are incorporated into international agreements (Finnemore, 1996; Finnemore \& Sikkink, 1998) In summary, it is argued that domestic elite 
sport policy is exposed to some explicit pressures to converge, but a far wider range of 'softer' forces arising from the socialisation into the dominant norms of the international elite sport community. It is also likely that the softer forces as well as the quasi-legal ones will impact across all dimensions of policy identified in Figure 1.

The advocacy coalition framework (ACF) is one of the more comprehensive attempts to analyse the policy process (Sabatier \& Jenkins-Smith, 1993; Sabatier \& Jenkins-Smith, 1999; for an application in relation to sport see Green \& Houlihan, 2005). According to the ACF policy sub-systems such as sport tend to generate competing domestic coalitions which vie for influence over resources and the direction of policy and as such could be seen as forces for divergence. The endogenous competition between coalitions in the sub-system is mediated by two sets of exogenous constraints, the first of which,is the 'relatively stable parameters, such as constitutional arrangements and fundamental socio-cultural values, which might also exert a constraining force on convergence. However, the second set of exogenous factors may be more likely to exert pressures for convergence and include: socio-economic conditions and technology (developments in sports science or in coaching fashions); changes in political control at the systemic level (new governments or Prime Ministers); public opinion; and policy spillover from contiguous policy sub-systems (such as from education, health and foreign affairs). Agency contributes to policy change in part through the competition between coalitions, but also in part through the activities of policy brokers who mediate coalition conflict and "whose principal concern is to find some reasonable compromise that will reduce intense conflict” (Sabatier \& Jenkins-Smith, 1999, p. 122).

However, the ACF acknowledges the limitations on the capacity of policy subsystems to insulate themselves from exogenous forces and emphasises the significance for policy choice and implementation of policy learning and transfer defined by Jenkins-Smith and Sabatier (1993, p. 44) as "an on-going process of search and adaptation”. The 
homogenising potential of policy learning through the continuous scanning of the policy environment is reinforced by the acknowledgement of the cumulative impact of evidence on policy selection (Rose 2005). In summary, while the focus of the ACF is on explaining policy making in domestic policy sub-systems the framework does give substantial weight to forces and processes which can exert powerful pressure for convergence. However, the concepts of policy learning and transfer assume that the same lessons will be learnt by a variety of observers, that what is transferred will be uniform rather than selective and that embedding the transferred policy will be unproblematic - all rather rash assumptions. As noted above in relation to the role of street level bureaucrats policy learning and transfer are likely to be highly political processes at the point of delivery as policy is, often of necessity, adapted to suit local conditions (Lipsky 2010). Finally, if effective learning and transfer takes place it is more likely that it will be in relation to inputs and implementation processes than in other dimensions.

Policy convergence would appear to be far less amenable to explanation if one applies John Kingdon's multiple streams framework of the policy process which gives greater emphasis to chance and contingency in the policy process. The three streams that he identifies are: the problem stream in which problems capture the attention of policy-makers as a consequence, for example, of a crisis or scandal; the political stream, which includes lobbying activity and the role of public opinion; and the third is the policy stream - solutions looking for suitable problems. The conjunction of the three streams is achieved when a 'policy window' opens due to the coincidence of favourable circumstances often aided by the activity of a 'policy entrepreneur'. According to one of Kingdon's interviewees “[Government] stumbles into paradoxical situations that force it to move one way or another. There are social forces that you can identify, but what comes out of them is just an accident” (1984, p.199). However, Kingdon also notes that there are structural constraints within the 
policy process, such as budgets, resource distribution and public opinion, which place a boundary on the extent of "residual randomness" (1984, p.199).

If one accepts the plausibility of Kingdon's pluralist model of the policy process then the potential for identifying and explaining convergence would appear to be extremely limited: correspondingly, if convergence is identified then it would appear to undermine the foundations of Kingdon’s model. However, Kingdon does note the significance of structure as a constraining force on actor agency. In relation to elite level sport the potential impact of structure is considerable. Not only are international federations in monopoly positions with regard to determining eligibility to compete and the rules of competition but they also, in many sports, control the most important competitions. In addition, event organising bodies such as the IOC and the Commonwealth Games Federation have had, due to the status of their competitions, a substantial impact in shaping the pattern of investment by governments in elite level sport. Kingdon would also accept that structural constraints might also take the form of ideas. Indeed in Harrison et al.'s investigation of convergence between UK and US healthcare systems using Kingdon's model they conclude that “our case strongly suggests the importance of ideational convergence, both in terms of the 'framing' of the problem and of the intellectual underpinnings of the purported solution” (2002, p. 19). As well as operating within a set of powerful institutional structures elite sport policy also operates within an intellectual climate of the steady medicalisation of sport (Waddington, 2000) and a more faddish scientisation $^{2}$ of sport (for example, the long term athlete development model which has gained rapid currency despite a weak evidence base, (Ford et al., 2011). It should also be borne in mind that neither organisational structures nor ideas are independent of underlying power distributions.

The concepts of policy learning and transfer form elements of a number of more comprehensive analytic frameworks and draw attention to the ubiquity of the process of 
borrowing ideas from other countries (Dolowitz and Marsh, 2000; Rose, 2005). Exactly what is learnt and transferred can be highly variable. At one end of the spectrum broad philosophies of government (e.g., the adoption of neo-liberal models of government such as New Public Management by New Zealand and Japan which were both strongly influenced by the experiments with NPM in the United States and the UK in the 1980s) through to more specific programmes (such as the Long Term Athlete Development model), funding models (national lotteries) and initiatives (youth talent search). In relation to sport the evidence supporting the extensive adoption of policy transfer is considerable. Often prompted by the perceived intractability of a particular problem (match-fixing, rising childhood obesity, young athlete burn-out or medal failure at a major international sport events) there are many examples of countries scanning their policy environment to find example of good practice or at least better policies than they currently implement. The poor performances by Canada at the 1960 Rome Olympics, Australia in Montreal in 1976 and the United Kingdom in the 1996 Atlanta Games all resulted in international searches for more successful policy. More recently, policy learning and transfer has become a much more routine activity with the UK and Japan, for example, systematically searching for examples of innovation and good practice in relation to sport science and coaching (Yamamoto, 2008).

The idea of mimetic isomorphism is derived in part from institutional theory which states that institutions compete not only for resources, but also for institutional legitimacy (DiMaggio \& Powell, 1983) and in part from organisational ecology. While the 'market' (for example, competition for public funding by national governing bodies of sport) is important in shaping the structure and policies of organisations these organisations function within a socially constructed normative world in which organisations experience pressure to conform to the social rules of their environment. Pressures for conformity are experienced more intensely at times of environmental uncertainty, resource shortage (a desire to save on search 
costs) and time pressure when organisations seek to reduce their exposure to risk by imitating each other (Cyert \& March, 1963). Thus role imitation occurs, according to March (1981) once a sufficient proportion of the same ecological population (i.e. similar organisations) begin to exhibit common practices and organisational forms: the common practices become normalised and taken for granted. Although this theory is usually applied to the analysis of the behaviour of business organisations it can readily be applied in the context of government departments. The theory is attractive at a commonsense level and is also supported by a considerable body of empirical research (see for example Phelps \& Dickson, 2009; Phelps \& Kent, 2010; Leiter, 2005; Ordanini et al., 2008; Edwards et al., 2009). The theory also overlaps with the theorisation of policy regimes discussed above and the softer form of regime influence through socialisation. What distinguishes regime theory from mimetic isomorphism is that the former process is underpinned by a deliberate attempt by the core supporters of the regime's values to export those values and embed them in other organisations or countries whereas mimetic isomorphism is seen as a 'natural' adjustment to the particular circumstances of the organisational environment. However, one of the key criticisms of the theory, and one that is especially pertinent to the present paper, is that it is less successful in explaining why some businesses diverge from the safety of the mainstream (see for example, Barreto \& Baden-Fuller, 2006).

Path dependency would appear to impede convergence given that it is based on the premise that current policy choices are constrained to varying degrees by previous policy choices (David, 2007; Houlihan, 2009; Kay, 2005; Peters et al., 2005). For example, it might be argued that, in relation to anti-doping policy, once an organisation (such as the World Anti-Doping Agency) has embarked on an anti-doping strategy reliant on sanctions to deliver objectives it not only becomes increasingly difficult to change direction (for example from punishment to education as the policy's central pillar), but the 'easiest' next step to take is 
always to increase the extent or scale of punishment - i.e. to stay on the same path. As has been illustrated so often in relation to sport, movement from an established policy path (whether that has been non-intervention in commercial or not-for-profit sport organisations, leaving the content of the PE curriculum to professional teachers or entrusting national governing bodies and their clubs to protect the welfare of young athletes) has required some external shock in the form of scandal or crisis which has dislodged the policy from current track and supporting interests.

The final theory concerns the impact of common circumstances, or 'parallel domestic pressures’ (Hoberg, 2001, p. 127) on the policy agenda. Among many western European countries it is possible to identify a number of social issues (integration of migrants, increasing obesity among the young and educational under-achievement by children from disadvantaged backgrounds, for example) for which a sport-based intervention has been prescribed. If a group of countries is experiencing a common set of problems it is reasonable to hypothesise that there would be some similarity in the response and hence a degree of convergence. Convergence is thus less the outcome of deliberate external intervention (through the requirements of an international convention or charter for example) and more the result of adjustments to changes in the environment which are often very gradual and have no direct relationship to the sport policy sub-sector.

\section{Methodological issues}

During the discussion of the dimensions and the frameworks a number of methodological issues have been identified. Four are of especial relevance to the testing of convergence hypotheses namely: the time period over which convergence should be assessed; the distance 
or altitude at which the assessment of convergence should take place; the operationalization of the concept of similarity; and the unit of analysis.

As regards the time period over which the assessment should be conducted Sabatier and Jenkins-Smith (1993) argue that a time frame of less than ten years is inadequate for assessing policy change and it is difficult to argue that a shorter time period would be a sufficient basis for drawing conclusions regarding convergence. Even in policy areas where evidence of success or failure of policy is easily determined (for example, in relation to elite success) each country might require a significant catalyst (for example, notable failure to meet public and media expectations of acceptable performance or political imperatives external to sport) to prompt a break with current policy and the possibility of a shift in a convergent direction. Thus while it has been argued that there is significant convergence in relation to elite sport development policy the period over which that convergence has taken place stretches back to the early 1960s when the Soviet Union designed its successful talent identification and development system which was subsequently copied by other Warsaw Pact countries and later by western countries - a period of over forty years. In other areas of sport, policy change has been less obviously in a convergent direction. Community sport/sport for all appeared to be on a convergent path in many western European countries after the prompt given by the Council of Europe's Sport for All Charter in the mid 1970s, but has, over the last twenty years, exhibited periods of acceleration towards convergence followed by periods of retreat across a range of countries indicating either that this aspect of sport policy is characterised by divergence (Nicholson et al., 2011) or that convergence is taking place, but more slowly and more falteringly. The complexity of the temporal aspect suggests that a period of ten years is a minimum requirement and that in relation to some aspects of sport policy a much longer timeframe is essential. 
'Altitude' refers to the distance from the phenomenon of policy change or the level of generality of the analysis. It is argued that the further one moves away from a micro level of analysis to a societal, regional or global viewpoint the more likely one is to identify convergence as local peculiarities and detail are blurred and consequently many claims to convergence are sustainable only at the higher levels of generality. The challenge of identifying the appropriate distance is easily illustrated. For example, is it sufficient simply to compare aggregate levels of adult participation between countries over time in order to draw conclusions about convergence? If national level aggregate data are considered to be too crude then how far should disaggregation go? Disaggregation by gender, ethnicity, income, age and region are all conventional in studies of participation and, with the exception of gender, could be broken down into much smaller units of analysis with the almost inevitable consequence that what might have been described as evidence of convergence when viewed at the aggregate level now looks like diversity or only limited convergence. Judging the optimal distance or altitude depends on the specific hypothesis to be tested. Thus a concern to investigate the extent to which sport has become more salient to governments could be assessed at a relatively high level through an analysis of national budget allocations and ministerial seniority whereas an analysis of hypotheses relating to convergence in the teaching of physical education to girls would require a level of analysis much closer to the ground and the point of delivery of PE teaching.

The concept of similarity is, as discussed at the beginning of the paper, integral to analyses of convergence yet as a number of authors (for example Sartori, 1991; Seeliger, 1996) have noted the concept of 'similarity' is unhelpfully elastic and invites the application of arbitrary decisions regarding the threshold for the designation of similarity with one consequence being the difficulty of testing conclusions. To some extent this problem is ameliorated by the disaggregation of the concept of convergence into a series of relatively 
discrete dimensions, but that alone does not solve the problem. It is consequently essential to identify and utilise quantitative measures of convergence wherever possible and to make clear the weight that is being given to the various elements of qualitative data that have been collected (see Holzinger, 2006, for a discussion of attempts to apply quantitative measures to convergence). In this way while the problem of measurement is not quite resolved there is the clear opportunity for other researchers to evaluate and challenge the significance granted to both quantitative and qualitative data.

The final issue to address concerns the appropriate unit of analysis. At first sight the answer is clear and that the unit of analysis should be the national sport policy sub-sector. However, in few if any countries sport policy is a self-contained sub-system: indeed in most countries sport policy is significantly affected by policy change in other more politically salient sub-sectors such as education, diplomacy, tourism and health. A recurring problem for sport policy-making is its permeability and its vulnerability to policy spillover from much more powerful policy sectors. Consequently, we need to take account of the possibility that what one might identify as convergence in sport policy (for example, investment in elite sport development or investment in community sport facilities) is simply a spillover from a process of convergence in other sub-systems such as the diplomatic (using elite sport as a 'soft power’ resource) or tourism (developing sport facilities in tourist destinations). While the impact of those decisions external to the sport sub-system may lead to convergence in aspects of sport the aspirations are those of policy actors external to sport.

\section{Conclusion}

In the introduction to this paper it was suggested that among the most pressing questions related to discussions of convergence were the following: 'Under what conditions can we 
expect convergence in sport policy?', What is the current extent, direction and pace of convergence?' and 'Is it possible to distinguish between shallow and deep policy convergence?'. It is suggested that the framework outlined in this paper enables substantial progress to be made in answering each of these questions. As regards the first question (the conditions under which convergence might be expected) the first three dimensions (motives, agenda and aspirations, and contextualising discourse/ ideology/values) provide an opportunity to investigate aspects of convergence which are often pre-conditions for more substantive and tangible evidence of convergence. Furthermore, when the dimensions are investigated within the context of one or more of the meso-level explanatory frameworks outlined in Table 3 it is possible to generate hypotheses that are amenable to empirical investigation, for example in relation to the existence of policy regimes or the significance of path dependency. The second question is always going to be more problematic for while the seven dimensions of convergence summarised in Table 1 can provide a 'snapshot' of the extent of convergence across a group of countries (or other units of analysis) identifying ‘direction' and calibrating 'pace' is more challenging. However, direction can be examined through analysis of motives (both explicit and implicit) and expressed aspirations while conclusions regarding 'pace' can be drawn, at least in part, on the basis of analyses of the length of time between statements of policy aspirations and the commitment of (adequate) resources. The measurement of both 'pace' and 'direction' require a longitudinal research design and the identification of key indicators. In relation to elite sport development key indicators might include change in budget allocations, specialist facility provision and investment in sports science/medicine and coach development. Investigation of this question would benefit from being sensitised by reference to meso level frameworks such as policy learning and mimetic isomorphism. The third question (distinguishing between shallow and deep policy convergence) requires reference to the levels of ideological embeddedness 
outlined in Table 2. Each of the seven dimensions can be analysed in terms of depth of social embeddedness. While the contextualising discourse can easily be conceptualised in terms of levels or depth so too can less obvious dimensions. For example, the decision to alter the mix of inputs to give a greater role to the public sector would, for some countries such as America and Japan, represent a profoundly significant change which challenges long held views about the limits of state action.

As the interest in comparative sport policy analysis increases it is essential that key concepts are defined clearly and are operationalised in such a way as to provide a basis on which valid conclusions can be drawn. It has been argued in this paper while the early explorations of convergence fulfilled the important function of opening up the field of study they also demonstrated the limitations of the utility of the concept as it was then defined. However, the purpose of this paper was not to highlight the limitations of earlier work as it is acknowledged that it provided the foundation on which a more sophisticated body on research could be established. The challenge that faces contemporary researchers is to build on this foundation and provide comparative analyses which explore and illuminate the complexity and richness of sport policy change and provide a clearer understanding of the extent and nature of processes such as convergence.

\section{References}

Alexiadou, N., Fink-Hafner, D., \& Lange, B. (2010). Education Policy Convergence through the Open Method of Coordination: theoretical reflections and implementation in 'old' and 'new' national contexts. European Educational Research Journal, 9, 345-358. 
Avdeyeva, O. (2006). In support of mothers’ employment: Limits to policy convergence in the EU? International Journal of Social Welfare, 15, 37-49.

Bachrach, P., \& Baratz, M.S. (1962). Two faces of power. The American Political Science Review, 56, 947-52.

Barreto, I., \& Baden-Fuller, C. (2006). To conform or to perform? Mimetic behaviour, legitimacy-based groups and performance consequences. Journal of Management Studies, 43, 1559-1581.

Bennett, B.L., Howell M.L. \& Simri, U. (1975). Comparative physical education and sport. Baltimore: Lee and Febiger.

Bennett, C.J. (1991). Review article: What is policy convergence and what causes it? British Journal of Political Science, 21, 215-33.

Benson, K. (1982). Networks and policy sectors: A framework for extending interorganisational analysis. In D. Rogers \& D. Whitten. Inter-organisational coordination, Iowa: Iowa State University.

Bergsgard, N.A., Houlihan, B., Mangset, P., Nødland, S.I. \& Rommetvedt, H. (2007). Sport policy: A comparative analysis of stability and change. Oxford: ButterworthHeinemann. 
Checkel, J.T., (2005). International institutions and socialization in Europe: introduction and framework. International Organization, 59, 801-826.

Coleman, W., \& Grant, W. (1998). Policy convergence and policy feedback: Agriculatural finance policies in a globalising era. European Journal of Political Research, 34, 225247.

Cox, R., (2004). The path dependency of an idea: Why Scandinavian welfare states remain distinct, Social Policy and Administration, 38.2, 204-19.

Cyert, R.M., \& March, J.G. (1963). A behavioral theory of the firm. Englewood Cliffs, NJ: Prentice-Hall.

David, P.A. (2007). Path dependence: A foundational concept for historical social science. Cliometrica, 1, 91-114.

Davison, G.J. (1995). The Cold War and the evolution of a sports consciousness in America. Sporting Heritage, 1, 91-103.

Deacon, B. (2000). Eastern European welfare states: the impact of the politics of globalisation., Journal of European Social Policy, 10, 146-161.

De Bosscher, V. (2007). Sports policy factors leading to international sporting success. Brussels, VUBPRESS. 
De Bosscher, V., De Knop, P., van Bottenburg, M., Shibli, S., \& Bingham, J. (2009). Explaining international sporting success: An international comparison of elite sport systems and policies in six countries. Sport Management Review, 12, 113-136.

Department of Culture, Media and Sport/Strategy Unit (2002). Game Plan: A strategy for delivering government's sport and physical activity objectives. London: DCMS/Strategy Unit.

De Bosscher, V. \& van Bottenburg, M. (2011). An assessment of the impact of sports development on sports participation. In B. Houlihan, B. \& M. Green (Eds.) Routledge handbook of sports development, London: Routledge.

DiMaggio, P.J., \& Powell, W.W. (1983). The iron cage revisited: institutional isomorphism and collective rationality in organizational fields. American Sociological Review, 48, 147-160.

Dolowitz, D., \& Marsh, D. (2000). Learning from abroad: The role of policy transfer in contemporary policymaking. Governance, 13, 5-23,

Downs, A. (1972). Up and down with ecology - the 'issue attention cycle'. Public Interest, 28, summer, 38-50.

Drezner, D.W. (2001). Globalization and policy convergence. International Studies Review, 3, 53-78. 
Dunn, B. (2004). Global restructuring and the power of Labour, Basingstoke: Palgrave.

Edelman, M. (1971). Politics as symbolic action. Chicago, IL: University of Illinois Press.

Edelman, M. (1977) Political language: Words that succeed and policies that fail. New York: Academic Press.

Edwards, J.R., Mason, D.S., \& Washington, M. (2009). Institutional pressures, government funding and provincial sport management. International Journal of Sport Management and Marketing, 6, 128-49.

Esping-Andersen, G. (1990). The three worlds of welfare capitalism. Cambridge: Polity Press.

Finnemore, M. (1996). Norms, culture and world politics: Insights from sociology’s institutionalism. International Organisation, 50, 325-48.

Finnemore, M., \& Sikkink, K. (1998) International norm dynamics and political change. International Organisation, 52, 887-917.

Fischer, F. (2003). Reframing public policy: Discursive politics and deliberative practices. New York: Oxford University Press. 
Ford,P., De Ste Croix, M., Lloyd, R., Meyers, R., Moosavi, M.. Oliver, J., Till, K., \& Williams, C. (2011). The long-term athlete development model: Physiological evidence and application. Journal of Sport Sciences, 29, 389-402.

Fransen, L. (2011). Why do private governance organisations not converge? A politicalinstitutional analysis of transnational labor standards regulation, Governance, 24, 359387.

Goldfinch, S. (2006). Rituals of reform, policy transfer, and the National University Corporation reforms of Japan. Governance, 19, 585-604.

Goldfinch, S., \& Wallis, J. (2010). Two myths of convergence in public management reform, Public Administration, 88, 1099-1115.

Gough, I., \& Abu Sharkh, M. (2011) Financing welfare regimes: Mapping heterogeneous revenue structures. International Journal of Social Welfare, 20, 1-12.

Green, M., \& Houlihan, B. (2005) Elite sport development: Policy learning and political priorities. London: Routledge.

Greve, B. (2011). Editorial introduction: The Nordic welfare states - revisited. Social_Policy and Administration. 45, 111-13.

Guttmann, A. (1984). The Games must go on: Avery Brundage and the Olympic movement. New York: Columbia University Press. 
Harrison, S., Moran, M., \& Wood, B. (2002). Policy emergence and policy convergence: the case of 'scientific-bureaucratic medicine' in the United States and the United Kingdom. British Journal of Politics and International Relations, 4, 1-24.

Harvey, J. (2006). Sport and Quebec nationalism: Ethnic or civic identity? In J. Sugden and A. Bairner (Eds.) Sport in divided societies (pp. 31-50), Verlag DE: Aachen: Meyer and Meyer.

Henry, I. \& the Institute of Sport and Leisure Policy. (2010). Transnational and comparative research in sport. London: Routledge.

Hoberg, G. (2001). Globalisation and policy convergence: Symposium overview. Journal of Comparative Policy Analysis: Research and Practice, 3, 127-132.

Holzinger, K. (2006). Methodological pitfalls of convergence analysis. European Union Politics, 7, 271-287.

Holzinger, K., \& Knill, C. (2005). Causes and conditions of cross-national policy convergence. Journal of European Public Policy, 12, 775-796.

Hood, C.C. \& Margetts, H. (2007). The tools of government in the digital age. Basingstoke: Macmillan.

Houlihan, B. (1997). Sport, policy and politics: A comparative analysis. London: Routledge. 
Houlihan, B. (2009). Mechanisms of international influence on elite sport policy. International Journal of Sport Policy, 1, 51-70.

Houlihan, B., \& Green, M. (Eds.). (2008). Comparative elite sport development: Systems, structures and public policy. Oxford: Butterworth-Heinemann.

Houlihan, B., Tan, T-C,, \& Green, M. (2010). China and the Olympic movement. Journal of Sport and Social Issues, 34, 4-28,

Jenkins-Smith, H., \& Sabatier, P. (1993). The dynamics of policy-oriented learning. In P.A. Sabatier \& H. Jenkins-Smith (Eds.). Policy change and learning: An advocacy coalition approach. Boulder, CO: Westview Press.

Jones, T., \& Newburn, T. (2002). Policy convergence and crime control in the USA and the UK: Streams of influence and levels of impact. Criminology and Criminal Justice, 2, 173-203.

Kay, A. (2005). A critique of the use of path dependency in policy studies. Public Administration, 83, 553-571.

Kerr, C. (1983) The future of industrial societies: Convergence or continuing diversity? Cambridge, MASS: Harvard University Press.

Kingdon, J. (1984). Agendas, alternatives, and public policy. New York: Harper Collins. 
Krasner, S., (1983). Structural causes and regime consequences: regimes as intervening variables. In S. Krasner (Ed.), International regimes 1-22. Ithica, NY: Cornell University Press.

Leiter, J. (2005). Structural isomorphism in Australian non-profit organisations. Voluntas, 16, $1-31$.

Liebfried, S. (1992). Towards a European welfare state? On integrating poverty regimes into the European Community. In F.Zsuzsa \& J.E. Kolberg (Eds.), Social policy in changing Europe, 245-280, Frankfurt: Capus Verlag and Westview Press.

Lindblom, C.E. (1977). Politics and markets. New York: Basic Books.

Lipsky, M. (2010). Street-level bureaucracy: Dilemmas of the individual in public services. New York: Russell Sage Foundation.

Mandle, W.F. (1976). Cricket and Australian nationalism in the nineteenth century. In T. Jaques, \& G. Pavia (Eds.), Sport in Australia: Selected readings, Sydney: McGrawHill.

March, J.G. (1981). Decisions in organisations and theories of choice. In A.H. van de Ven \& W.F. Joyce (Eds.), Perspectives on organisation design and behaviour. New York: Wiley. 
March, J. \& Olsen, J. (1996). Institutional perspectives on political institutions. Governance, 9, 247-64.

McBride, S. \& Williams, R.A. (2001). Globalisation, the restructuring of labour markets and policy convergence: The OECD ‘job strategy’, Global Social Policy, 1, 281-309.

Moynihan, D. (2006). Managing for results in state-government: Evaluating a decade of reform. Public Administration Review, 66, 77-90.

Muncie, J. (2005). The globalisation of crime control - the case of youth and juvenile justice: Neo-liberalism, policy convergence and international conventions. Theoretical Criminology, 9, 35-64.

Nicholson, M., Hoye, R., \& Houlihan, B. (Eds.) (2011). Participation in sport: International policy perspectives. London: Routledge.

Ordanini, A., Rubera, G., \& DeFillippi, R. (2008). The many modes of inter-organisational imitation: A critical review. International Journal of Management Reviews, 10, 375398.

Ozga, J. (2004). Pressures for Convergence and Divergence in Education: Devolution in the Context of Globalisation', Working Paper 2, Edinburgh: Centre for Educational Sociology, University of Edinburgh.

Peppard, V., \& Riordan, J. (1993). Playing politics: Soviet sports diplomacy to 1992. Greenwick, CONN.: JAI Press Inc. 
Peters, B.G., Pierre, J., \& King, D.S. (2005). The politics of path dependency: Political conflict in historical institutionalism. Journal of Politics, 67, 1275-1300.

Phelps, S., \& Dickson, G. (2009). Symbolic isomorphism and legitimacy: New Zealand’s Ice Blacks and Ice Fernz. International Journal of Sport Management and Marketing, 5, 90-100.

Phelps, S., \& Kent, A. (2010). Isomorphism and choice in the creation and development of an international sport federation: A review of the International Triathlon Union. International Journal of Sport Management and Marketing, 8, 277-395.

Premfors, R. (1998). Reshaping the democratic state: Swedish experiences in a comparative perspective. Public Administration, 76, 141-59.

Pressman, J.L., \& Wildavsky, A. (1984). Implementation ( $3^{\text {rd }}$ ed.). Berkley, CA: University of California Press.

Radaelli, C.M. (2005). Diffusion without convergence: How political context shapes the adoption of regulatory impact assessment. Journal of European Public Policy, 12, 924-943.

Raffe, D. (2004). How distinctive is Scottish Education? Five perspectives on distinctiveness. Scottish Affairs, 49, autumn, 50-72.

Riordan, J. (Ed.) (1978). Sport under communism. London: Hurst. 
Risse, T., Ropp, S. \& Sikkink, K., (Eds.) (1999). The power of human rights: international norms and domestic change. Cambridge: Cambridge University Press.

Rodger, B. (1978). Sport in its social context: International comparisons. Strasbourg: Council of Europe.

Rose, R. (2005). Learning from comparative public policy: A practical guide. London: Routledge.

Sabatier, P.A., \& Jenkins-Smith, H. (1993). Policy change and learning: An advocacy coalition approach. Boulder, CO: Westview Press.

Sabatier, P.A., \& Jenkins-Smith, H. (1999). The advocacy coalition framework: An assessment. In P.A. Sabatier (Ed.). Theories of the policy process: Theoretical lenses on the public policy. 189-220, Boulder, CO: Westview Press.

Sartori, G. (1991). Comparing and miscomparing. Journal of Theoretical Politics, 3, 243257.

Seeliger, R. (1996). Conceptualising and researching policy convergence. Policy Studies Journal, 24, 287-306.

Siaroff, A. (1994). Work, women and gender equality: A new typology, In D. Sainsbury (Ed.) Gendering welfare states. 82-100, London: Sage. 
Simri, U. (1979). Comparative physical education and sport., Natanya, Israel: Wingate Institute.

Strenk, A. (1978). Diplomats in tracksuits: linkages between sports and foreign policy in the German Democratic Republic. In B. Lowe, D.B. Kanin \& A. Strenk(Eds.) Sport and international relations. Champaign, Ill.: Stipes.

Tanaka, N. (2012) The development of disability sport policy in Japan and the UK. Unpublished PhD thesis, Loughborough University, UK.

Taylor-Gooby, P. (2003). Open markets versus welfare citizenship: Conflicting approaches to policy convergence in Europe. Social Policy and Administration, 37, 539-554.

Thomas, N. (2008). Sport and disability. In B. Houlihan (Ed.) Sport and society: A student introduction. 205-229, London: Sage.

United Nations (1989). Convention on the rights of the child. Retrieved from http://www2.ohchr.org/english/law/crc.htm

United Nations (2008). Convention on the rights of persons with disabilities. Available at http://treaties.un.org/Pages/ViewDetails.aspx?src=TREATY\&mtdsg_no=IV$\underline{15 \& \text { chapter }=4 \& \text { lang }=\text { en }}$

Vij, R. (2007). Globalization and welfare: A critical reader. Basingstoke: Palgrave. 
Waddington, I. (2000). Sport, health and drugs: A critical sociological perspective. London: Routledge.

Wilson, J. (1988). Politics and leisure. Boston: Unwin.

World Anti-Doping Agency. (2009). World Anti-Doping Code. Montreal: WADA.

Xu, G. (2009). Olympic dreams: China and sport 1895-2008. Cambridge, MASS.: Harvard University Press.

${ }^{1}$ This distinction was prompted by Edelman's work on symbolic politics (Edelman 1971 \& 1977).

${ }^{2}$ Scientisation refers to the elevation of professional judgement and practitioner intuition to the level of robust scientific evidence often through the adoption of the terminology and forms of presentation found in the natural sciences. 